\title{
Three Parameters to Find Functional Decompositions
}

\author{
Tsutomu Sasao \\ Ken-ichi Kurimoto \\ Department of Computer Science and Electronics \\ Kyushu Institute of Technology \\ Iizuka 820-8502, Japan
}

\begin{abstract}
Finding simple disjoint functional decompositions is a basic problem, but is generally timeconsuming since there are nearly $2^{n}$ bipartitions of input variable. This paper introduces three parameters to find bipartitions of the input variables. It also defines "ideal random logic functions," and derives their properties. Experimental results using randomly generated functions and benchmark functions show the usefulness of the approach.
\end{abstract}

\section{INTRODUCTION}

Decompositions of logic functions have been studied for many years [1,4]. A function $f$ has a simple disjoint decomposition if $f$ is represented as $f\left(X_{1}, X_{2}\right)=$ $g\left(h\left(X_{1}\right), X_{2}\right)$. To find decompositions for look-up-table type FPGA, the number of variables in $X_{1}$ may be at most five $[6,10,21]$. So, the number of bipartitions to consider is $C(n, 5)$, where $n$ is the number of the input variables.

However, to find general decompositions, the number of variables in $X_{1}$ is unbounded, and we have to consider nearly $2^{n}$ different bipartitions $\left(X_{1}, X_{2}\right)$ of input variables $\left\{x_{1}, x_{2}, \ldots, x_{n}\right\}$. When $n$ is large, the number of bipartitions to consider is too large, but the exhaustive search is impractical.

Roughly speaking, decomposition methods can be classified into two: Exhaustive methods [2, 8, 9, 14, 16, 18, $20,22]$ and heuristic methods $[3,5,23,11,12]$. Exhaustive methods find all possible decompositions, but they are usually time consuming. On the other hand, heuristic methods find only a part of all possible decompositions, but they are relatively fast.

This paper, we will consider a heuristic method to find decompositions. For the heuristics, we introduce three parameters. By using these parameters, we can efficiently find decompositions.

The rest of the paper is organized as follows: Section II gives definitions and basic properties. Section III introduces two parameters, and show their application to find decompositions of cascade realizable functions. Section IV introduces "ideal random logic functions," as well as an another parameter. We will derive the properties of these parameters. Section $\mathrm{V}$ is the experimental results showing effectiveness of these approaches by using randomly generated functions and benchmark functions.

For the page limitation, all the proofs are omitted.

\section{Definitions And Basic Properties}

\section{Definition 2.1}

$$
\begin{aligned}
\frac{d f}{d x_{i}}= & f\left(x_{1}, x_{2}, \ldots, \stackrel{i}{0}, x_{i+1}, \ldots, x_{n}\right) \\
& \oplus f\left(x_{1}, x_{2}, \ldots, \stackrel{i}{1}, x_{i+1}, \ldots, x_{n}\right)
\end{aligned}
$$

is a Boolean difference of $f$ with respect to $x_{i}$.

Lemma 2.1 Let $f$ and $g$ be functions of $x, y, z, \ldots$ Then, we have the following:

1. $\frac{d \bar{f}}{d x}=\frac{d f}{d x}$,

2. $\frac{d f}{d x}=\frac{d f}{d \bar{x}}$,

3. $\frac{d(f \cdot g)}{d x}=f \cdot \frac{d g}{d x} \oplus g \cdot \frac{d f}{d x} \oplus \frac{d f}{d x} \cdot \frac{d g}{d x}$,

4. $\frac{d(f \oplus g)}{d x}=\frac{d g}{d x} \oplus \frac{d f}{d x}$,

5. $\frac{d(f \vee g)}{d x}=\bar{f} \cdot \frac{d g}{d x} \oplus \bar{g} \cdot \frac{d f}{d x} \oplus \frac{d f}{d x} \cdot \frac{d g}{d x}$, and

6. $\frac{d}{d x}\left(\frac{d f}{d y}\right)=\frac{d}{d y}\left(\frac{d f}{d x}\right)$

Lemma 2.2 When $f$ does not depend on $x$, and $g$ depends on $x$, we have the followings:

1. $\frac{d f}{d x}=0$,

2. $\frac{d(f \cdot g)}{d x}=f \cdot \frac{d g}{d x}$, and

3. $\frac{d(f \vee g)}{d x}=\bar{f} \cdot \frac{d g}{d x}$.

Definition 2.2 Let $\left(X_{1}, X_{2}\right)$ be a bipartition of $X=$ $\left(x_{1}, x_{2}, \ldots, x_{n}\right)$. If $f$ is represented as $f\left(X_{1}, X_{2}\right)=$ $g\left(h\left(X_{1}\right), X_{2}\right)$, then $f$ has a simple disjoint decomposition. Variables in $X_{1}$ are bound variables, and variables in $X_{2}$ are free variables.

Lemma 2.3 Let $f$ be decomposed as $f\left(X_{1}, X_{2}\right)=$ $g\left(h\left(X_{1}\right), X_{2}\right)$. If $x_{1} \in X_{1}$, then

$$
\frac{d f}{d x_{1}}=\frac{d g}{d h} \frac{d h}{d x_{1}} .
$$




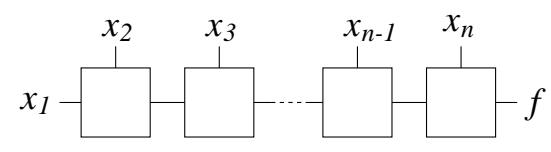

Fig. 3.1. Cascade network.

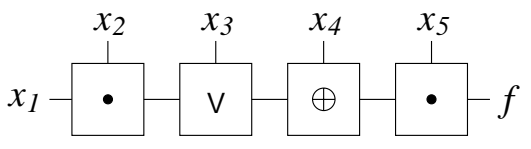

Fig. 3.2. Cascade network of five variables.

\section{Cascade Realization}

In this section, we will introduce two parameters that are useful to find variable orderings for cascade realizable functions.

Definition 3.1 Let $f$ be an n-variable logic function. The number of true minterms in $f$ is denoted by $w(f)$. $d=w(f) / 2^{n}(0 \leq d \leq 1)$ is the density of $f$, and denoted by $\operatorname{den}(f)$.

Lemma 3.1 Let $h_{1}\left(X_{1}\right)$ and $h_{2}\left(X_{2}\right)$ be functions with densities $d_{1}$ and $d_{2}$, respectively, where $\left\{X_{1}\right\} \cap\left\{X_{2}\right\}=\phi$. Then, $\operatorname{den}\left(h_{1}\left(X_{1}\right) h_{2}\left(X_{2}\right)\right)=d_{1} d_{2}$.

Lemma 3.2 Let $x$ be a variable of $h$. Then

$$
\frac{1}{2} \operatorname{den}\left(\frac{d h}{d x}\right) \leq \min \{\operatorname{den}(h), \operatorname{den}(\bar{h})\} .
$$

Lemma 3.3 Let $h(X)$ be an arbitrary logic function. Let $x_{k}$ be a variable in $\{X\}$, and let $x_{k+1}$ be a variable not in $\{X\}$.

When $f=x_{k+1} \vee h(X)$.

$$
\frac{d f}{d x_{k+1}}=\bar{h}(X) \text { and } \frac{d f}{d x_{k}}=\bar{x}_{k+1}\left(\frac{d h}{d x_{k}}\right) .
$$

When $f=x_{k+1} h(X)$.

$$
\frac{d f}{d x_{k+1}}=h(X) \text { and } \frac{d f}{d x_{k}}=x_{k+1} \frac{d h}{d x_{k}} .
$$

When $f=x_{k+1} \oplus h(X)$.

$$
\frac{d f}{d x_{k+1}}=1 \text { and } \frac{d f}{d x_{k}}=\frac{d h}{d x_{k}} .
$$

Theorem 3.1 Let $f\left(x_{1}, x_{2}, \ldots, x_{n}\right)$ be realized by a cascade network of two-input gates as shown in Fig. 3.1. Then, $\operatorname{den}\left(\frac{d f}{d x_{i}}\right) \leq \operatorname{den}\left(\frac{d f}{d x_{j}}\right)$, for $i<j$.

Example 3.1 Consider the cascade network shown in Fig. 3.2. Note that $f=\left[\left(x_{1} x_{2} \vee x_{3}\right) \oplus x_{4}\right] x_{5}$.

$$
\begin{aligned}
\frac{d f}{d x_{1}} & =x_{2} \bar{x}_{3} x_{5}, \\
\frac{d f}{d x_{2}} & =x_{1} \bar{x}_{3} x_{5}, \\
\frac{d f}{d x_{3}} & =\left(\bar{x}_{1} \vee x_{1} \bar{x}_{2}\right) x_{5}, \\
\frac{d f}{d x_{4}} & =x_{5}, \text { and } \\
\frac{d f}{d x_{5}} & =\left(x_{1} x_{2} \vee x_{3}\right) \oplus x_{4} .
\end{aligned}
$$

Thus, we have

$$
\begin{aligned}
& \operatorname{den}\left(\frac{d f}{d x_{1}}\right)=\frac{2}{16}, \\
& \operatorname{den}\left(\frac{d f}{d x_{2}}\right)=\frac{2}{16}, \\
& \operatorname{den}\left(\frac{d f}{d x_{3}}\right)=\frac{6}{16}, \\
& \operatorname{den}\left(\frac{d f}{d x_{4}}\right)=\frac{8}{16}, \text { and } \\
& \operatorname{den}\left(\frac{d f}{d x_{5}}\right)=\frac{8}{16} .
\end{aligned}
$$

Note that $\operatorname{den}\left(\frac{d f}{d x_{i}}\right) \leq \operatorname{den}\left(\frac{d f}{d x_{j}}\right)(1 \leq i<j \leq 5)$.

(End of Example)

As shown in Theorem 3.1, $\operatorname{den}\left(\frac{d f}{d x_{i}}\right)$ is a parameter that shows the ordering of the variable in the cascade realizations. Next, we will introduce an another parameter that also shows the ordering of the variables.

Definition 3.2 Let $f$ be an $n$-variable function such that $f=\bar{x}_{i} f_{0} \vee x_{i} f_{1}$.

$$
\rho\left(f: x_{i}\right)=\left|w\left(f_{0}\right)-w\left(f_{1}\right)\right|=\left|w(f)-2 w\left(f_{1}\right)\right|
$$

and $i=1,2, \ldots, n$.

\section{Lemma 3.4}

1) $\rho\left(f: x_{i}\right)=\rho\left(\bar{f}: x_{i}\right)$.

2) $\rho\left(f: x_{i}\right)=\rho\left(f: \bar{x}_{i}\right)$.

Lemma 3.5 Let $x$ be a variable, and $g$ be an $(n-1)$ variable function that does not depend on $x$. Then,

$$
w(x \oplus g)=2^{n-1} .
$$

Theorem 3.2 Let $f\left(x_{1}, x_{2}, \ldots, x_{n}\right)$ be realized by a cascade network of two-input gates as shown in Fig. 3.1. Then, $\rho\left(f: x_{i}\right) \leq \rho\left(f: x_{j}\right)$, for $1 \leq i<j \leq n$.

Example 3.2 Consider the function $f=\left[\left(x_{1} x_{2} \vee x_{3}\right) \oplus\right.$ $\left.x_{4}\right] x_{5}$, which appeared in Example 3.1.

$$
\begin{aligned}
\rho\left(f: x_{1}\right) & =w\left(\left(x_{3} \oplus x_{4}\right) x_{5}\right)-w\left(\left[\left(x_{2} \vee x_{3}\right) \oplus x_{4}\right] x_{5}\right) \\
& =4-4=0, \\
\rho\left(f: x_{2}\right) & =w\left(\left(x_{3} \oplus x_{4}\right) x_{5}\right)-w\left(\left[\left(x_{1} \vee x_{3}\right) \oplus x_{4}\right] x_{5}\right) \\
& =4-4=0, \\
\rho\left(f: x_{3}\right) & =w\left(\left(x_{1} x_{2} \oplus x_{4}\right) x_{5}\right)-w\left(\bar{x}_{4} x_{5}\right)=4-4=0, \\
\rho\left(f: x_{4}\right) & =w\left(\left(x_{1} x_{2} \vee x_{3}\right) x_{5}\right)-w\left(\left(x_{1} x_{2} \vee x_{3}\right) x_{5}\right) \\
& =5-3=2, \\
\rho\left(f: x_{5}\right) & =\left|w(0)-w\left(\left(x_{1} x_{2} \vee x_{3}\right) \oplus x_{4}\right)\right|=8 .
\end{aligned}
$$




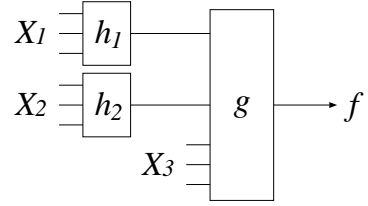

Fig. 4.1. Decomposition $f\left(X_{1}, X_{2}, X_{3}\right)=g\left(h_{1}\left(X_{1}\right), h_{2}\left(X_{2}\right), X_{3}\right)$.

Thus, $\rho\left(f: x_{i}\right) \leq \rho\left(f: x_{j}\right),(1 \leq i<j \leq 5)$. (End of Example)

As shown in this section, $\operatorname{den}\left(\frac{d f}{d x_{i}}\right)$ and $\rho\left(f: x_{i}\right)$ show the ordering of variables in cascade realizable functions.

\section{Ideal Random Logic Functions}

In the previous section, we showed that $\operatorname{den}\left(\frac{d f}{d x_{i}}\right)$ is useful to find bipartitions for cascade realizable functions. However, only a fraction of the functions are cascade realizable. In this section, we will introduce ideal random logic functions, and show that $\operatorname{den}\left(\frac{d f}{f x_{i}}\right)$ and $\operatorname{den}\left(\frac{d^{2} f}{d x_{i} d x_{j}}\right)$ are useful to find decompositions for a class of functions.

Definition 4.1 Ideal random logic functions have the following properties:

1) Let $f(X)=\bar{x}_{i} f_{0} \vee x_{i} f_{1}$ be an ideal random logic function, and let the density of $f$ be $d$. Then, $f_{0}$ and $f_{1}$ are also ideal random logic functions with the densities $d$ for all $i \in\{1,2, \ldots, n\}$.

2) Let $f_{1}(X)$ and $f_{2}(X)$ be two different ideal random logic functions with densities $d_{1}$ and $d_{2}$, respectively. Then, $\operatorname{den}\left(f_{1}(X) f_{2}(X)\right)=d_{1} d_{2}$.

Lemma 4.1 Let $f$ be an ideal random logic function with density $d$. Then, den $(d f / d x)=2 d(1-d)$.

Lemma 4.2 Let $g$ and $h$ be ideal random logic functions with densities $d_{g}$ and $d_{h}$, respectively. Let $f$ be decomposed as $f\left(X_{1}, X_{2}\right)=g\left(h\left(X_{1}\right), X_{2}\right)$. When $x_{i}$ is in $\left\{X_{1}\right\}$, $A=\operatorname{den}\left(\frac{d f}{d x_{i}}\right)=4 d_{g} d_{h}\left(1-d_{g}\right)\left(1-d_{h}\right)$. When $x_{i}$ is in $\left\{X_{2}\right\}, B=\operatorname{den}\left(\frac{d f}{d x_{i}}\right)=2 d_{g}\left(1-d_{g}\right)$.

Since $A / B=2 d_{h}\left(1-d_{h}\right) \leq 1 / 2$ in Lemma 4.2 , we have the following:

Theorem 4.1 Let $f$ be decomposable as $f\left(X_{1}, X_{2}\right)=$ $g\left(h\left(X_{1}\right), X_{2}\right)$, where $g$ and $h$ are ideal random logic functions. If $x_{i} \in\left\{X_{1}\right\}$ and $x_{j} \in\left\{X_{2}\right\}$, then $w\left(\frac{d f}{d x_{i}}\right)<$ $w\left(\frac{d f}{d x_{j}}\right)$.

Lemma 4.3 Let $\left(X_{1}, X_{2}, X_{3}\right)$ be a partition of $X$, and $f$ be decomposed as $f\left(X_{1}, X_{2}, X_{3}\right)=g\left(h_{1}\left(X_{1}\right), h_{2}\left(X_{2}\right)\right.$, $\left.X_{3}\right)$, where $g, h_{1}$, and $h_{2}$ are ideal random logic functions with densities $d_{g}, d_{h_{1}}$, and $d_{h_{2}}$, respectively (See Fig. 4.1). Also, assume that the Boolean differences of $g, h_{1}$, and $h_{2}$ are also ideal random logic functions.
1) When $x_{1}, x_{2} \in\left\{X_{1}\right\}$.

$$
\begin{aligned}
A & =\operatorname{den}\left(\frac{d^{2} f}{d x_{1} d x_{2}}\right) \\
& =8 d_{g}\left(1-d_{g}\right) d_{h_{1}}\left(1-d_{h_{1}}\right)\left(1-2 d_{h_{1}}+2 d_{h_{1}}^{2}\right) .
\end{aligned}
$$

2) When $x_{1} \in\left\{X_{1}\right\}$ and $x_{2} \in\left\{X_{2}\right\}$.

$$
\begin{aligned}
B= & \operatorname{den}\left(\frac{d^{2} f}{d x_{1} d x_{2}}\right) \\
= & 16 d_{g}\left(1-d_{g}\right)\left(1-2 d_{g}+2 d_{g}^{2}\right) \\
& d_{h_{1}}\left(1-d_{h_{1}}\right) d_{h_{2}}\left(1-d_{h_{2}}\right) .
\end{aligned}
$$

3) When $x_{1} \in\left\{X_{1}\right\}$ and $x_{2} \in\left\{X_{3}\right\}$.

$$
\begin{aligned}
C & =\operatorname{den}\left(\frac{d^{2} f}{d x_{1} d x_{2}}\right) \\
& =8 d_{g}\left(1-d_{g}\right)\left(1-2 d_{g}+2 d_{g}^{2}\right) d_{h_{1}}\left(1-d_{h_{1}}\right) .
\end{aligned}
$$

4) When $x_{1}, x_{2} \in\left\{X_{3}\right\}$.

$$
D=\operatorname{den}\left(\frac{d^{2} f}{d x_{1} d x_{2}}\right)=4 d_{g}\left(1-d_{g}\right)\left(1-2 d_{g}+2 d_{g}^{2}\right) \text {. }
$$

Theorem 4.2 Let $\left(X_{1}, X_{2}, X_{3}\right)$ be a partition of $X$, and $f$ be decomposed as $f\left(X_{1}, X_{2}, X_{3}\right)=g\left(h_{1}\left(X_{1}\right), h_{2}\left(X_{2}\right)\right.$, $\left.X_{3}\right)$, where $g, h_{1}$, and $h_{2}$ are ideal random logic functions with densities $d_{g}, d_{h_{1}}$, and $d_{h_{2}}$, respectively (See Fig. 4.1). Also, assume that the Boolean differences of $g, h_{1}$, and $h_{2}$ are also ideal random logic functions. If $x_{1} \in\left\{X_{1}\right\}$, $x_{2} \in\left\{X_{2}\right\}$, and $x_{3 A}, x_{3 B} \in\left\{X_{3}\right\}$, then

$$
\operatorname{den}\left(\frac{d^{2} f}{d x_{1} d x_{2}}\right)<\operatorname{den}\left(\frac{d^{2} f}{d x_{1} d x_{3 A}}\right)<\operatorname{den}\left(\frac{d^{2} f}{d x_{3 A} d x_{3 B}}\right) .
$$

As shown in this section, $\operatorname{den}\left(\frac{d f}{d x_{i}}\right)$ and $\operatorname{den}\left(\frac{d^{2} f}{d x_{i} d x_{j}}\right)$ are useful to find the decompositions of functions that are composed of ideal random logic functions.

\section{Experimental Results}

In many cases, the given functions are not cascade realizable nor composed of ideal random logic functions. However, parameters introduced in Section III are still useful to find bipartitions for disjoint decompositions. To see the usefulness of the parameters, we constructed multi-level networks by using randomly generated functions.

A. Decomposition of $f=g\left(g\left(X_{1}\right), X_{2}\right)$, where $\left|X_{1}\right|=5$.

We randomly generated a five-variable function $g$, where $w(g)=12$, and constructed the network shown in Fig. 5.1.

Note that $f=g\left(g\left(X_{1}\right), X_{2}\right)$, where $X_{1}=$ $\left(x_{1}, x_{2}, x_{3}, x_{4}, x_{5}\right)$ and $X_{2}=\left(x_{6}, x_{7}, x_{8}, x_{9}\right)$. Table 5.1 shows the values of $\rho\left(f: x_{i}\right)$ and $w\left(\frac{d f}{d x_{i}}\right)$. The values of $\rho\left(f: x_{i}\right)$ tend to be greater for free variables. However, $\rho\left(f: x_{8}\right)=0$ even if $x_{8}$ is a free variable. So, $\rho\left(f: x_{i}\right)$ is not so a reliable parameter. On the other hand, the values of $w\left(\frac{d f}{d x_{i}}\right)$ for free variables are always greater than ones for bound variables. 


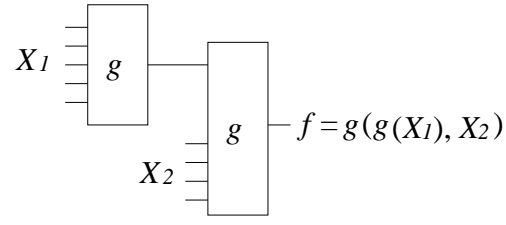

Fig. 5.1. Generation of a function $f=g\left(g\left(X_{1}\right), X_{2}\right)$.

TABLE 5.1

Parameters for a 9-variable function $f=g\left(g(1), X_{2}\right)$.

\begin{tabular}{|l|rrrrr|rrrr|}
\hline & \multicolumn{5}{|c|}{$X_{1}$} & \multicolumn{4}{|c|}{$X_{2}$} \\
& $x_{1}$ & $x_{2}$ & $x_{3}$ & $x_{4}$ & $x_{5}$ & $x_{6}$ & $x_{7}$ & $x_{8}$ & $x_{9}$ \\
\hline$\rho\left(f: x_{i}\right)$ & 0 & 0 & 0 & 0 & 0 & 24 & 40 & 0 & 24 \\
$w\left(\frac{d f}{d x_{i}}\right)$ & 100 & 120 & 100 & 120 & 100 & 152 & 192 & 152 & 192 \\
\hline
\end{tabular}

B. Decomposition of $f=g\left(g\left(X_{1}\right), g\left(X_{2}\right), X_{3}\right)$, where $\left|X_{1}\right|=5$.

To see the effectiveness of the parameters $\operatorname{den}\left(\frac{d^{2} f}{d x_{i} d x_{j}}\right)$, we did the following: We used the same random function $\mathrm{g}$ to construct the network shown in Fig. 5.2, where $X_{1}=\left(x_{1}, x_{2}, \ldots, x_{5}\right), X_{2}=\left(x_{6}, x_{7}, \ldots, x_{10}\right)$, and $X_{3}=$ $\left(x_{11}, x_{12}, x_{13}\right)$.

Table 5.2 shows the values of $\rho\left(f: x_{i}\right)$ and $w\left(\frac{d f}{d x_{i}}\right)$. Also in this case, we can observe that the parameters for the free variables are larger than ones for the bound variables.

Table 5.3 shows the values of $w\left(\frac{d^{2} f}{d x_{i} d x_{j}}\right)$. The results are consistent with Theorem 4.2:

1) When $x_{i} \in X_{1}$ and $x_{j} \in X_{2}, 200 \leq w\left(\frac{d^{2}}{d x_{i} d x_{j}}\right) \leq 288$.

2) When $x_{i} \in X_{1}$ and $x_{j} \in X_{3}, 640 \leq w\left(\frac{d^{2}}{d x_{i} d x_{j}}\right) \leq 768$.

3) When $x_{i}, x_{j} \in X_{3}, 640 \leq w\left(\frac{d^{2}}{d x_{i} d x_{j}}\right) \leq 928$.

However, in this case, these parameters are not sufficient to find the bipartition of the variables. The maximum value 1152 occurs when $\left(x_{i}, x_{j} \in X_{1}\right)$ or $\left(x_{i} \in X_{2}\right.$ and $\left.x_{j} \in X_{3}\right)$. Also, the value 640 occur for many cases.

One reason for this is that $g$ and $\frac{d f}{d x_{i}}$ do not satisfy the conditions of ideal random logic functions. We consider that to be ideal random logic functions, the number of variables in $g$ should be larger.

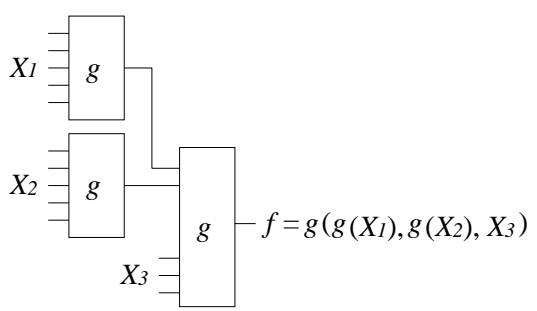

Fig. 5.2. Generation of a function $f=g\left(g\left(X_{1}\right), g\left(X_{2}\right), X_{3}\right)$.
C. Decomposition of $f=g\left(g\left(X_{1}\right), g\left(X_{2}\right), X_{3}\right)$, where $\left|X_{1}\right|=7$.

We generated a random function $g$ of 7 variables, where $w(g)=64$. And, constructed the network shown in Fig. 5.2, where $X_{1}=\left(x_{1}, x_{2}, \ldots, x_{7}\right), X_{2}=$ $\left(x_{8}, x_{9}, \ldots, x_{14}\right)$, and $X_{3}=\left(x_{15}, x_{16}, \ldots, x_{19}\right)$.

Table 5.4 shows the values of $w\left(\frac{d^{2} f}{d x_{i} d x_{j}}\right)$. In this case, the results better support Theorem 4.2:

1) When $x_{i} \in X_{1}$ and $x_{j} \in X_{2}, 8064 \leq w\left(\frac{d^{2}}{d x_{i} d x_{j}}\right) \leq$ 20216.

2) When $x_{i} \in X_{1}$ and $x_{j} \in X_{3}, 18432 \leq w\left(\frac{d^{2}}{d x_{i} d x_{j}}\right) \leq$ 38912.

3) When $x_{i}, x_{j} \in X_{3}, 49152 \leq w\left(\frac{d^{2}}{d x_{i} d x_{j}}\right) \leq 90112$.

\section{Other Benchmark Functions}

In most cases, logic functions used in industries are nonrandom. However, we can use these parameters to find decompositions by using the following:

\section{Algorithm 5.1}

1. Partition the multiple-output function into singleoutput functions, and decompose each function separately. Generate the BDD for each function.

2. If there is a level with width two, then decompose the function into two, and apply this step recursively.

3. Use $w\left(\frac{d f}{d x_{i}}\right)$ to order the input variables, and reorder the variables in the $B D D$ to find decompositions. If tie, use $\rho\left(f: x_{i}\right)$ to order the variables. If tie, check the symmetry of the variables.

Table 5.5 compares the numbers of decompositions found by Algorithm 5.1 and ones found by DECOMPOS [16]. In Table 5.5, PAR denotes the number of blocks after decompositions using Algorithm 5.1; JAC denotes the number of blocks after decompositions using DECOMPOS [16], and OUT denotes the number of outputs. Note that DECOMPOS finds all the disjoint decompositions.

$$
\text { Ratio }=\frac{(P A R-O U T)}{(J A C-O U T)} \times 100
$$

denotes the percentage of the decompositions found by Algorithm 5.1. Note that C1355 has no decomposition. Except for a few cases (i.e., C1908, b3 and x6dn), Algorithm 5.1 found considerable part of decompositions.

\section{Conclusions}

In this paper, we introduced three parameters to find disjoint decompositions. $\rho\left(f: x_{i}\right)$ and $w\left(\frac{d f}{d x_{i}}\right)$ show the influence of the variables in the networks: The greater the values, the more influential the variables. Thus, the less influential variables are candidates for bound variables.

Since these parameters are relatively easily calculated, any functional decomposition systems can incorporate this method. 
TABLE 5.2

Parameters for a 13-variable function $f=g\left(g(1), g\left(X_{2}\right), X_{3}\right)$.

\begin{tabular}{|l|rrrrr|rrrrr|rrr|}
\hline & \multicolumn{9}{|c|}{$X_{1}$} & \multicolumn{1}{c|}{$X_{2}$} & \multicolumn{3}{c|}{$X_{3}$} \\
& $x_{1}$ & $x_{2}$ & $x_{3}$ & $x_{4}$ & $x_{5}$ & $x_{6}$ & $x_{7}$ & $x_{8}$ & $x_{9}$ & $x_{10}$ & $x_{11}$ & $x_{12}$ & $x_{13}$ \\
\hline$\rho\left(f \dot{f} x_{i}\right)$ & 48 & 48 & 0 & 48 & 0 & 16 & 16 & 0 & 16 & 0 & 448 & 960 & 160 \\
$w\left(\frac{d f}{d x_{i}}\right)$ & 1920 & 2304 & 1920 & 2304 & 1920 & 1600 & 1920 & 1600 & 1920 & 1600 & 2368 & 3168 & 2368 \\
\hline
\end{tabular}

TABLE 5.3

Parameters for a 13-variable function $f=g\left(g(1), g\left(X_{2}\right), X_{3}\right)$.

\begin{tabular}{|rl|rrrrr|rrrrr|rrr|}
\hline & & \multicolumn{1}{|c|}{$X_{1}$} & \multicolumn{1}{c|}{$X_{2}$} & & & $X_{3}$ \\
& & $x_{1}$ & $x_{2}$ & $x_{3}$ & $x_{4}$ & $x_{5}$ & $x_{6}$ & $x_{7}$ & $x_{8}$ & $x_{9}$ & $x_{10}$ & $x_{11}$ & $x_{12}$ & $x_{13}$ \\
\hline & $x_{1}$ & 0 & 768 & 768 & 768 & 768 & 200 & 240 & 200 & 240 & 200 & 640 & 640 & 640 \\
& $x_{2}$ & 768 & 0 & 384 & 768 & 768 & 240 & 288 & 240 & 288 & 240 & 768 & 768 & 768 \\
$X_{1}$ & $x_{3}$ & 768 & 384 & 0 & 768 & 1152 & 200 & 240 & 200 & 240 & 200 & 640 & 640 & 640 \\
& $x_{4}$ & 768 & 768 & 768 & 0 & 384 & 240 & 288 & 240 & 288 & 240 & 768 & 768 & 768 \\
& $x_{5}$ & 768 & 768 & 1152 & 384 & 0 & 200 & 240 & 200 & 240 & 200 & 640 & 640 & 640 \\
\hline & $x_{6}$ & 200 & 240 & 200 & 240 & 200 & 0 & 640 & 640 & 640 & 640 & 720 & 560 & 960 \\
& $x_{7}$ & 240 & 288 & 240 & 288 & 240 & 640 & 0 & 320 & 640 & 640 & 864 & 672 & 1152 \\
$X_{2}$ & $x_{8}$ & 200 & 240 & 200 & 240 & 200 & 640 & 320 & 0 & 640 & 960 & 720 & 560 & 960 \\
& $x_{9}$ & 240 & 288 & 240 & 288 & 240 & 640 & 640 & 640 & 0 & 320 & 864 & 672 & 1152 \\
& $x_{10}$ & 200 & 240 & 200 & 240 & 200 & 640 & 640 & 960 & 320 & 0 & 720 & 560 & 960 \\
\hline & $x_{11}$ & 640 & 768 & 640 & 768 & 640 & 720 & 864 & 720 & 864 & 720 & 0 & 928 & 928 \\
$X_{3}$ & $x_{12}$ & 640 & 768 & 640 & 768 & 640 & 560 & 672 & 560 & 672 & 560 & 928 & 0 & 640 \\
& $x_{13}$ & 640 & 768 & 640 & 768 & 640 & 960 & 1152 & 960 & 1152 & 960 & 928 & 640 & 0 \\
\hline
\end{tabular}

\section{ACKNOWLEDGMENTS}

This work was supported in part by a Grant in Aid for Scientific Research of the Ministry of Education, Science, Culture and Sports of Japan, as well as the Takayanagi Foundation for Electronics Science and Technology. Mr. M. Matsuura formatted the $\mathrm{LAT}_{\mathrm{E}} \mathrm{X}$ files.

\section{REFERENCES}

[1] R. L. Ashenhurst, "The decomposition of switching functions," In Proceedings of an International Symposium on the Theory of Switching, pp. 74-116, April 1957.

[2] V. Bertacco and M. Damiani, "The disjunctive decomposition of logic functions," Proc. ICCAD, pp. 78-82, 1997.

[3] S. C. Crist, "Synthesis of combinational logic using decomposition and probability," IEEE Trans. Comput., Vol. C-29, No. 11, pp. 1013-16, Nov. 1980.

[4] H. A. Curtis, A New Approach to the Design of Switching Circuits, D. Van Nostrand Co., Princeton, NJ, 1962.

[5] E. V. Dubrova, D. M. Miller, J. C. Muzio, "On the relation between disjunctive decomposition and ROBDD variable ordering," 1997 IEEE Pacific Rim Conference on Communications, Computers and Signal Processing, PACRIM. 10 Years Networking the Pacific Rim, 19871997, pp. 688-691 Vol. 2, 2 Vol. xxiii+1021, 1997.

[6] Ting-Ting Hwang, R. M. Owens, M. J. Irwin, and Kuo Hua Wang, "Logic synthesis for field-programmable gate arrays," IEEE Trans. Comput.-Aided Des. Integr. Circuits Syst., Vol. 13, No. 10, pp. 1280-1287, Oct. 1994
[7] Y-T. Lai, M. Pedram, and S. B. K. Vrudhula, "EVBDDbased algorithm for integer linear programming, spectral transformation, and functional decomposition," IEEE Trans. CAD, Vol. 13, No. 8, pp. 959-975, Aug. 1994.

[8] Y. Matsunaga, "An exact and efficient algorithm for disjunctive decomposition," SASIMI'98, pp. 44-50, Oct. 1998.

[9] S. Minato and G. De Micheli, "Finding all simple disjunctive decompositions using irredundant sum-of-products forms," ICCAD-98, pp. 111-117, Nov. 1998.

[10] R. Murgai, R. K. Brayton, and A. SangiovanniVincentelli, Logic Synthesis for Field-Programmable Gate Arrays, Kluwer, 1995.

[11] M. Rawski, L. Jozwiak, and T. Luba, "Efficient input support selection for sub-functions in functional decomposition based on information relationship measures," Euromicro 1999, Milan, Sept. 1999.

[12] J. T. Proudfoot and S. M. Ngwira, "Non-exhaustive method for identification of optimal variable orderings in the decomposition of complex logic functions," IEE Proc., Comput. Digit. Tech., Vol. 142, No. 5, pp. 373-5, Sept. 1995.

[13] J. P. Roth and R. M. Karp, "Minimization over Boolean graphs," IBM Journal of Research and Development, pp. 227-238, April 1962.

[14] T. Sasao, "FPGA design by generalized functional decomposition," in (Sasao ed.) Logic Synthesis and Optimization, Kluwer Academic Publishers, 1993. 
TABLE 5.4

Parameters for 19-variable function $f=g\left(g(1), g\left(X_{2}\right), X_{3}\right)$.

\begin{tabular}{|c|c|c|c|c|c|c|c|c|c|c|c|c|c|c|c|c|c|c|c|c|}
\hline & \multicolumn{7}{|c|}{$X_{1}$} & \multicolumn{7}{|c|}{$X_{2}$} & \multicolumn{5}{|c|}{$X_{3}$} \\
\hline & & $x_{1}$ & $x_{2}$ & $x_{3}$ & $x_{4}$ & $x_{5}$ & $x_{6}$ & $x_{7}$ & $x_{8}$ & $x_{9}$ & $x_{10}$ & $x_{11}$ & $x_{12}$ & $x_{13}$ & $x_{14}$ & $x_{15}$ & $x_{16}$ & $x_{17}$ & $x_{18}$ & $x_{19}$ \\
\hline \multirow{7}{*}{$X_{1}$} & $x_{1}$ & 0 & 27648 & 24576 & 18432 & 27648 & 24576 & 30720 & 14336 & 14336 & 11648 & 17024 & 16128 & 10752 & 13440 & 32768 & 24576 & 24576 & 28672 & 24576 \\
\hline & $x_{2}$ & 27648 & 0 & 27648 & 30720 & 21504 & 18432 & 21504 & 14336 & 14336 & 11648 & 17024 & 16128 & 10752 & 13440 & 327 & 24576 & 24576 & 286 & 24576 \\
\hline & $x_{3}$ & 24576 & 27648 & 0 & 21504 & 24576 & 18432 & 24576 & 11648 & 11648 & 9464 & 13832 & 13104 & 8736 & 10920 & 26624 & 19968 & 19968 & 23296 & 19968 \\
\hline & $x_{4}$ & 18432 & 30720 & 21504 & 0 & 33792 & 21504 & 30720 & 17024 & $=17024$ & 13832 & 20216 & 19152 & 12768 & 15960 & 389 & 29184 & 29184 & 4340 & 29184 \\
\hline & $x_{5}$ & 27648 & 21504 & 24576 & 33792 & 0 & 18432 & 24576 & 16128 & 16128 & 13104 & 19152 & 18144 & 12096 & 15120 & 36864 & 27648 & 27648 & 32256 & 27648 \\
\hline & $x_{6}$ & 24576 & 18432 & 18432 & 21504 & 18432 & 0 & 21504 & 10752 & 10752 & 8736 & 12768 & 12096 & 8064 & 10080 & 24576 & 18 & 18432 & & 18432 \\
\hline & $x_{7}$ & 30720 & 21504 & 24576 & 30720 & 24576 & 21504 & 0 & 13440 & 13440 & 10920 & 15960 & 15120 & 10080 & 12600 & 30720 & 23040 & 23040 & 26880 & 23040 \\
\hline \multirow{7}{*}{$X_{2}$} & $x_{8}$ & 14336 & 14336 & 11648 & 17024 & 16128 & 10752 & 13440 & & 34560 & 30720 & 23040 & 34560 & 30720 & 38400 & 40960 & 28672 & 32768 & 40960 & 32768 \\
\hline & $x_{9}$ & 14336 & 14336 & 11648 & 17024 & 16128 & 10752 & 13440 & 34560 & 0 & 34560 & 38400 & 26880 & 23040 & 26880 & 40960 & 28672 & 32768 & 40960 & 32768 \\
\hline & $x_{10}$ & 11648 & 11648 & 9464 & 13832 & 13104 & 8736 & 10920 & 30720 & 34560 & 0 & 26880 & 30720 & 23040 & 30720 & 33280 & 23296 & 26624 & 133280 & 26624 \\
\hline & $x_{11}$ & 17024 & 17024 & 13832 & 20216 & 19152 & 12768 & 15960 & 23040 & 38400 & 26880 & 0 & 42240 & 26880 & 38400 & 48640 & 34048 & 38912 & 48640 & 38912 \\
\hline & $x_{12}$ & 16128 & 16128 & 13104 & 19152 & 18144 & 12096 & 15120 & 34560 & 26880 & 30720 & 42240 & 0 & 23040 & 30720 & 46080 & 32256 & 36864 & 446080 & 36864 \\
\hline & $x_{13}$ & 10752 & 10752 & 8736 & 12768 & 12096 & 8064 & 10080 & 30720 & 23040 & 23040 & 26880 & 23040 & 0 & 26880 & 30720 & 21504 & 24576 & 30 & 24576 \\
\hline & $x_{14}$ & 13440 & 13440 & 10920 & 15960 & 15120 & 10080 & 12600 & 38400 & 26880 & 30720 & 38400 & 30720 & 26880 & 0 & 38400 & 26880 & 30720 & 38400 & 30720 \\
\hline \multirow{4}{*}{$X_{3}$} & $x_{15}$ & 32768 & 32768 & 26624 & 38912 & 36864 & 24576 & 30720 & 40960 & 40960 & 33280 & 48640 & 46080 & 30720 & 38400 & & 73728 & 65536 & j 49152 & 73728 \\
\hline & $x_{16}$ & 24576 & 24576 & 19968 & 29184 & 27648 & 18432 & 23040 & 28672 & 28672 & 23296 & 34048 & 32256 & 21504 & 26880 & 73728 & 0 & 73728 & 8192 & 57344 \\
\hline & $x_{18}$ & 28672 & 28672 & 23296 & 34048 & 32256 & 21504 & 26880 & 40960 & 40960 & 33280 & 48640 & 46080 & 30720 & 38400 & 49152 & 81920 & 57344 & & 90112 \\
\hline & $x_{19}$ & 24576 & 24576 & 19968 & 29184 & 27648 & 18432 & 23040 & 32768 & 32768 & 26624 & 38912 & 36864 & 24576 & 30720 & 73728 & 57344 & 65536 & 90112 & 0 \\
\hline
\end{tabular}

TABLE 5.5

Functional decompositions using Algorithm 5.1.

\begin{tabular}{|l|r|r|r|r|r|}
\hline Data & & & \multicolumn{2}{|c|}{ \# Blocks } & Ratio \\
\cline { 4 - 5 } name & IN & OUT & PAR & JAC & $(\%)$ \\
\hline C1355 & 41 & 32 & 32 & 32 & - \\
C1908 & 33 & 25 & 26 & 94 & 1.4 \\
accpla & 50 & 69 & 564 & 703 & 78.1 \\
alu4 & 14 & 8 & 15 & 15 & 100.0 \\
apex1 & 45 & 45 & 257 & 266 & 96.0 \\
apex2 & 39 & 3 & 34 & 37 & 91.2 \\
apex5 & 117 & 88 & 512 & 870 & 54.2 \\
b3 & 32 & 20 & 122 & 183 & 62.6 \\
comp & 32 & 3 & 63 & 63 & 100.0 \\
des & 256 & 245 & 1080 & 1374 & 74.0 \\
frg2 & 143 & 139 & 1183 & 1227 & 96.0 \\
i3 & 132 & 6 & 126 & 126 & 100.0 \\
i4 & 192 & 6 & 186 & 186 & 100.0 \\
rck1 & 32 & 7 & 216 & 216 & 100.0 \\
signet & 39 & 8 & 27 & 32 & 79.2 \\
t481 & 16 & 1 & 15 & 15 & 100.0 \\
x2dn & 82 & 56 & 104 & 105 & 98.0 \\
x6dn & 39 & 5 & 14 & 36 & 29.0 \\
xparc & 41 & 73 & 689 & 752 & 90.7 \\
\hline
\end{tabular}

IN : Number of the input variables.

OUT: Number of the output variables.

PAR: Number of blocks after decompositions using Algorithm 5.1.

JAC: Number of blocks after decompositions using DECOMPOS [16].

Ratio $=\frac{(P A R-O U T)}{(J A C-O U T)} \times 100$.
[15] T. Sasao and J. T. Butler, "On bi-decompositions of logic functions," $A C M / I E E E$ International Workshop on Logic Synthesis, Tahoe City, California, May 1997.

[16] T. Sasao and M. Matsuura, "DECOMPOS: An integrated system for functional decomposition," 1998 International Workshop on Logic Synthesis, Lake Tahoe, June 1998.

[17] T. Sasao, Switching Theory for Logic Synthesis, Kluwer Academic Publishers (1999-02).

[18] T. Sasao, "Totally undecomposable functions: Applications to efficient multiple-valued decompositions," IEEE International Symposium on Multiple-Valued Logic, pp. 59-65, Freiburg, Germany, May 20-23, 1999.

[19] T. Sasao and S. Kajihara, "Functional decompositions using an automatic test pattern generators and a logic simulator," ACM/IEEE International Workshop on Logic Synthesis, Tahoe City, California, June 28-30, 1999.

[20] T. Sasao, "Arithmetic ternary decision diagrams and their applications," 4th International Workshop on Applications of the Reed-Muller Expansion in Circuit Design, Victoria, Canada, August, 1999.

[21] H. Sawada, T. Suyama, and A. Nagoya, "Logic synthesis for look-up table based FPGAs using functional decomposition and support minimization," ICCAD, pp. 353359, Nov. 1995.

[22] V. Y-S, Shen, A. C. Mckellar, and P. Weiner, "A fast algorithm for the disjunctive decomposition of switching functions," IEEE Trans. Comput., Vol. C-20, No. 3, pp. 304-309, March 1971.

[23] W-Z Shen, J-D Huang, and S-M Chao, "Lamda set selection in Roth-Karp decomposition for LUT-based FPGA technology mapping," 32nd Design Automation Conference, pp. 65-69, June 1995.

[24] S. Yang, "Logic synthesis and optimization benchmark user guide," Version 3.0, MCNC, Jan. 1991. 